06

\title{
Лазерное инициирование энергонасыщенных композитов на основе нанопористого кремния
}

\author{
(ㄷ Г.Г. Зегря, ${ }^{1}$ Г.Г. Савенков, ${ }^{1,2}$ А.Г. Зегря, ${ }^{1}$ В.А. Брагин, ${ }^{3}$ И.А. Оськин, ${ }^{3}$ У.М. Побережная ${ }^{2}$ \\ ${ }^{1}$ Физико-технический институт РАН им. А.Ф. Иоффре РАН, \\ 194021 Санкт-Петербург, Россия \\ ${ }^{2}$ Санкт-Петербургский государственный технологический институт (технический университет), \\ 90013 Санкт-Петербург, Россия \\ ${ }^{3}$ Научно-производственное объединение „Поиск“, \\ 188162 Мурино, Ленинградская обл., Россия \\ e-mail: sav-georgij@yandex.ru
}

Поступило в Редакцию 29 октября 2019 г.

В окончательной редакции 21 февраля 2020 г.

Принято к публикации 4 апреля 2020 г.

Представлены результаты экспериментов по лазерному инициированию взрывчатых превращений в энергонасыщенных композитах на основе нанопористого кремния. В качестве окислителя использовался перхлорат кальция. Показано, что добавка в энергонасыщенный композит (20-30) mass.\% графеноподобного порошкового материала приводит к увеличению его чувствительности к инфракрасному лазерному излучению и возбуждению в композите быстрых экзотермических реакций.

Ключевые слова: лазерное излучение, энергонасыщенный композит, нанопористый кремний, взрывчатое превращение.

DOI: $10.21883 /$ JTF.2020.10.49803.355-19

\section{Введение}

Лазерное инициирование энергонасыщенных материалов (ЭНМ), в частности взрывчатых веществ (ВВ), как альтернатива электрическому методу возбуждения взрыва достаточно давно находится в зоне пристального научного внимания специалистов в области физики горения и взрыва [1]. Так в [1,2] приведены краткие физические основы лазерного инициирования энергонасыщенных материалов. Использование лазерного излучения для непосредственного инициирования вторичных ВВ (вторичные ВВ, вещества, основной режим взрывчатого превращения которых - детонация, возбуждаемая действием взрыва, инициирующего ВВ) может обеспечить создание боеприпасов и других взрывных устройств без применения в них инициирующих взрывчатых веществ. Вторичные ВВ менее чувствительны к внешним воздействиям, чем инициирующие $\mathrm{BB}$, тем самым появляется возможность обеспечения более высокой безопасности указанных изделий во время эксплуатации, хранения и транспортировки.

Кроме того, с помощью лазерного инициирования можно добиться высокого быстродействия взрывных устройств [2]. Для этого необходимы лазеры, работающие в импульсном режиме. Однако в этом случае, несмотря на явное преимущество перед электрическим способом инициирования, с точки зрения нечувствительности к зарядам статического электричества, блуждающим токам и действию электромагнитных полей, у такого вида лазерного инициирования есть большой недостаток. Поясним данное утверждение.
Под действием интенсивного лазерного излучения в зарядах ЭНМ, которые (если они не содержат металлические добавки) в подавляющем большинстве являются диэлектриками, может произойти нагрев поверхностного слоя или макро-, микрообъема вещества, или разрушение (оптический пробой) заряда, или создание электронно-дырочных пар. Кроме того, в ряде случаев полагают, что некоторые взрывчатые вещества обладают слабыми полупроводящими свойствами с шириной запрещенной зоны $\varepsilon_{g}=1 \mathrm{eV}$ [3]. В этом случае может произойти рекомбинация электронно-дырочных пар с передачей энергии третьим носителям (электронам или дыркам), которые, поглощая переданную им энергию, переходят в высоковозбужденное состояние (так называемый оже-процесс) [4]. В результате таких процессов в заряде ЭНМ и возникают быстрые экзотермические реакции (взрывчатые превращения). Однако для этого требуется большая мощность лазерного излучения, что с точки зрения практического применения и является большим недостатком данного способа инициирования ВВ. Поэтому практическая реализация лазерных детонаторов в технических взрывных устройствах в настоящее время связана с применением полупроводниковых лазеров мощностью до $10 \mathrm{~W}$ [2]. Для уменьшения мощности предлагаются различные способы модифицирования ЭНМ (светопоглощающие [5] или светорассеивающие добавки [6]).

В то же время лазерное излучение позволяет изменять как макроскопическое, так и микроскопическое состояние практически любых материалов, включая ЭНМ. Основой этого явления является способность лазерного 
излучения избирательно возбуждать различные степени свободы физической системы, т. е. лазерным излучением с перестраиваемой частотой можно избирательно возбудить любые квантовые состояния атомов и молекул заданного сорта. Путем многоступенчатого возбуждения можно вводить в атомы или молекулы определенного типа значительную энергию, вызывая их избирательную фотоионизацию, фотодиссоциацию и другие фотопревращения. Это направление применения лазеров иногда называют селективной лазерной фотофизикой и фотохимией [7]. Селективное лазерное воздействие можно реализовать, используя явление оптического резонанса. При этом эффект лазерного воздействия оказывается очень чувствительным к характеристикам самого излучения.

Селективное возбуждение внутренних степеней свободы, по мнению авторов $[6,8]$, вероятно, связано с механизмом развития энергетически разветвленных цепных реакций (реакций с переходом химической энергии в энергию возбуждения внутренних степеней свободы образующихся частиц), инициируемых в ЭНМ при таком типе воздействия резонансного лазерного излучения. Введение светорассеивающих добавок, резонансных действующему лазерному излучению частиц некоторых веществ, в тетранитропентаэритрит (ТЭН) (самое чувствительное ВВ из бризантных взрывчатых веществ) в работах $[6,9]$ как раз связано с применением резонансного (селективного) лазерного воздействия на ЭНМ.

Однако введение в уже существующее взрывчатое вещество инертных добавок обладает такими недостатками как: 1) уменьшение энергетических характеристик ЭНМ; 2) снижение технологичности (появляется, как минимум, одна дополнительная технологическая операция) и, как следствие этого, повышение стоимости взрывчатой композиции.

Поэтому было бы интересно, с практической точки зрения, иметь такое взрывчатое вещество (взрывчатый состав), которое уже содержало бы в себе активные центры, резонансные действующему лазерному излучению. Отметим, что создание взрывчатых веществ и составов, селективно чувствительных к лазерному излучению с целью получения капсюльных составов для оптических (лазерных) детонаторов, продолжается достаточно длительное время (см. [5,9-11] и обзоры в них). В [1,2] также приведены краткие физические основы лазерного инициирования ЭНМ.

Настоящая работа посвящена лазерному инициированию взрывчатого состава - энергокомпозита (ЭК) на основе нанопористого кремния nanopor-Si (в качестве горючего) и перхлората кальция $\mathrm{Ca}\left(\mathrm{ClO}_{4}\right)_{2}$ (в качестве окислителя). Отметим, что энергокомпозиты (в том числе и исследуемый в настоящей работе) на основе nanopor-Si и перхлоратов достаточно давно вызывают большой интерес исследователей в области создания новых взрывчатых материалов [12]. Ниже будет показано, что ЭК на основе нанопористого кремния селективно чувствительны к лазерному излучению. Будут рассмотрены два типа композитов: первый тип - это ЭК на основе нанопористого кремния, без добавок; второй тип - это ЭК на основе нанопористого кремния с добавлением графеноподобного порошкового материала. Будет показано, что два типа композитов имеют разную спектральную чувствительность к возбуждению взрывчатого превращения.

\section{1. Энергокомпозит и теоретическое обоснование его инициирования селективным лазерным излучением}

Энергокомпозит на основе нанопористого кремния и перхлората кальция рассматривается в качестве возможной замены традиционных первичных ВB (например, азида свинца) [13]. Ранее такие энергокомпозиты показали достаточно высокую чувствительность к различным электрофизическим импульсам (к сильноточному электронному пучку наносекундной длительности, к высоковольтному разряду и к электрическому взрыву полупроводникового мостика) [14,15], а также к тепловому воздействию [16].

Технология получения нанопористого кремния, легированного бором (КДБ), обладающего дырочной электропроводностью, состоит в следующем. Для формирования нанопор пластины (толщиной $\sim 750 \mu \mathrm{m}$ ) монокристаллического кремния марки КДБ-100 с концентрацией носителей заряда $\sim 10^{19} \mathrm{~cm}^{-3}$ подвергали двухстороннему электрохимическому травлению в электролите, состоящем из плавиковой кислоты (40 mass.\%) и метанола в соотношении $1: 1$. Травление осуществляли при плотностях тока около $100 \mathrm{~mA} \cdot \mathrm{cm}^{2}$ в течение 50-60 min. В результате в пластинах формировались поры со средними размерами $12-15 \mathrm{~nm}$. Пористость пластин находилась в диапазоне $70-80 \%$. Таким образом, по классификации Международного союза по чистой и прикладной химии (IUPAC) полученный нами пористый кремний относится к мезопористым структурам. Пластины со сформированной мезопористой структурой измельчали и получали порошок со средним размером частиц $30-40 \mu \mathrm{m}$.

Образцы композита (заряда) из порошка nanopor-Si и перхлората кальция $\mathrm{Ca}\left(\mathrm{ClO}_{4}\right)_{2}$ получали следующим образом: в металлический колпачок высотой $4 \mathrm{~mm} \mathrm{c}$ внутренним диаметром $4 \mathrm{~mm}$ и с отверстием в донышке диаметром $3 \mathrm{~mm}$ запрессовывали под давлением $80 \mathrm{MPa}$ $18 \mathrm{mg}$ порошка nanopor-Si. Запрессованный порошок nanopor-Si пропитывали раствором $\mathrm{Ca}\left(\mathrm{ClO}_{4}\right)_{2}$ так, чтобы после испарения метанола массовое соотношение между $\mathrm{Ca}\left(\mathrm{ClO}_{4}\right)_{2}$ и порошком КДБ находилось на уровне $1: 1$. Высота заряда в колпачке $-3 \mathrm{~mm}$. Колпачки с зарядом полученного ЭК вначале помещали в емкость с хлористым метиленом (для полного испарения метанола). Затем колпачки помещались в термошкаф с температурой $80^{\circ} \mathrm{C}$ и высушивались в нем в течение $15 \mathrm{~min}$ до полного испарения остатков растворителя, что контролировалось 
путем взвешивания колпачков (их масса становилась постоянной).

Кроме того, в настоящей работе использовался энергокомпозит, содержащий кроме пористого кремния и перхлората кальция графеноподобный порошкообразный материал, полученный по технологии самораспространяющегося высокотемпературного синтеза технического лигнина [17] (в отличие от однослойного „классического“ графена в нашем случае было 5-7 слоев углерода). В этом случае технология получения такого энергокомпозита (образца/заряда) состояла в следующем. Порошки nanopor-Si и графеноподобного материала перемешивались вручную в соотношении между компонентами (nanopor-Si : graphene) $1: 0.5$ или $1: 1$ до получения однородного цвета. Затем из каждой полученной смеси изготавливали окончательные образцы, т.е. $18 \mathrm{mg}$ смеси запрессовывали в вышеописанные колпачки под тем же давлением $80 \mathrm{MPa}$. Запрессованный порошок смеси пропитывали раствором $\mathrm{Ca}\left(\mathrm{ClO}_{4}\right)_{2}$ так, чтобы после испарения метанола массовое соотношение между $\mathrm{Ca}\left(\mathrm{ClO}_{4}\right)_{2}$ и порошком nanopor-Si находилось на уровне $1: 1$. Таким образом, получали следующий энергокомпозит с соотношениями между компонентами (nanopor-Si : $\mathrm{Ca}\left(\mathrm{ClO}_{4}\right)_{2}:$ graphene) $1: 1: 1$ (ЭК-1) или $1: 1: 0.5$ (ЭК-2). Идея применения данного композита будет описан в разд. 2 .

Как представляется, в нашем случае возбуждение взрывчатых превращений в исследуемом (в основном nanopor- $\left.\mathrm{Si}+\mathrm{Ca}\left(\mathrm{ClO}_{4}\right)_{2}\right)$ энергокомпозите с помощью воздействия лазерного луча может проходить по двум механизмам. Первый механизм связан с термическим эффектом лазерного воздействия; второй механизм это чисто оптическое возбуждение взрывного процесса.

Известно, что кристаллический кремний - это непрямозонный полупроводник; экстремумы зоны проводимости находятся вблизи края зоны Бриллюэна, а вершина валентной зоны в центре зоны Бриллюэна. Следовательно, коэффициент поглощения существенно меньше, чем для прямозонных полупроводников.

В нанопористом кремнии ситуация принципиально другая. Благодаря квантованию энергетического спектра носителей заряда происходит подавление закона сохранения импульса, следовательно, коэффициент поглощения существенно возрастает. Спектр поглощения при этом становится очень широким и простирается от инфракрасного диапазона $10^{3} \mathrm{~nm}$ до ультрафиолетового примерно $400 \mathrm{~nm}$. Таким образом, при лазерном инициировании взрывчатого процесса в композитах с пористым кремнием, возможно резонансное возбуждение стенок nanopor-Si c последующей передачей энергии к окислителю с целью отрыва кислорода от хлора (если речь идет об использовании перхлората кальция в качестве окислителя). Закон дисперсии для кремния довольно сложный, кроме минимума в точке $X$, есть еще минимум на границе зоны Бриллюэна в точке $L$ [18]. Энергетическая щель для точки $L$ порядка $2.0 \mathrm{eV}$; это соответствует длине волны $620 \mathrm{~nm}$. В силу квантования энергетического спектра в пористом кремнии возможно прямое, бесфононное поглощение света с энергией кванта $\hbar \omega \geq 2.0 \mathrm{eV}$. Согласно [19], сечение поглощения равно:

$$
\sigma(\omega)=\sum_{e, h} \hbar \omega \hat{\sigma} L\left(E_{e}-E_{\hbar}-\hbar \omega\right)
$$

где

$$
\hat{\sigma}=\frac{8 \pi^{2}|F|^{2}}{3 n} \alpha|M|^{2}
$$

$F-$ фактор локального поля, учитывающий экранировку поля электромагнитной волны в пористом кремнии, $\alpha$ - постоянная тонкой структуры, $M-$ матричный элемент оптического перехода, $n-$ показатель преломления среды, $L-$ функция Лоренца с полушириной $\Delta$, параметр $\Delta$ определяет характерное уширение уровней энергии возбужденных состояний пористого кремния.

Следует отметить, что чем меньше длина волны лазерного излучения или, что то же самое, больше энергия кванта, тем больше сечение поглощения. При изменении длины волны лазера от 620 до $310 \mathrm{~nm}$ сечение поглощения изменяется более чем на три порядка.

В нашем случае для лазера с длиной волны $\lambda=405 \mathrm{~nm}$ сечение поглощения порядка $\sigma=5.5 \cdot 10^{-18} \mathrm{~cm}^{2}[19]$, что более чем достаточно для резонансного возбуждения быстрой экзотермической реакции.

Таким образом, можно полагать, что применение лазерного излучения с длинами волн $\lambda$, соответствующих частотам $\omega>\varepsilon_{g} / \hbar$, приведет к резкому увеличению коэффициента поглощения. Переход поглощенной энергии в тепловую приведет к резкому увеличению температуры в островках пористого кремния (которые будут являться аналогами горячих точек в теории механической и ударно-волновой чувствительности ВВ [20]), что в совокупности с окислителем обеспечит их возгорание и горение, а с увеличением интенсивности горения и объединения микроочагов горения в один большой макроочаг - переход горения во взрыв.

Второй механизм связан с фотодиссоциацией на связанно-свободных электронных переходах облучаемых молекул перхлората кальция, что приводит к образованию активных атомов или радикалов. А, как известно [21], через образование активных частиц идут цепные реакции горения или другого вида взрывчатого превращения.

Заметим, что механизм, связанный с фотодиссоциацией облучаемых кристаллов перхлората кальция в нанопористом кремнии, рассматривался в работе [22], в которой для облучения nanopor-Si с кислородом использовался импульсный азотный лазер (энергия квантов $h v=3.7 \mathrm{eV}$, длительность импульса $0.2 \mathrm{ps}$, плотность потока мощности $10^{4} \mathrm{~W} / \mathrm{cm}^{2}$ ).

На основании предполагаемых механизмов можно ожидать резкого снижения мощности лазерного излучения, необходимого для возбуждения взрывчатого превращения в зарядах из энергокомпозита на основе нанопористого кремния nano-Si и перхлората кальция $\mathrm{Ca}\left(\mathrm{ClO}_{4}\right)_{2}$. 

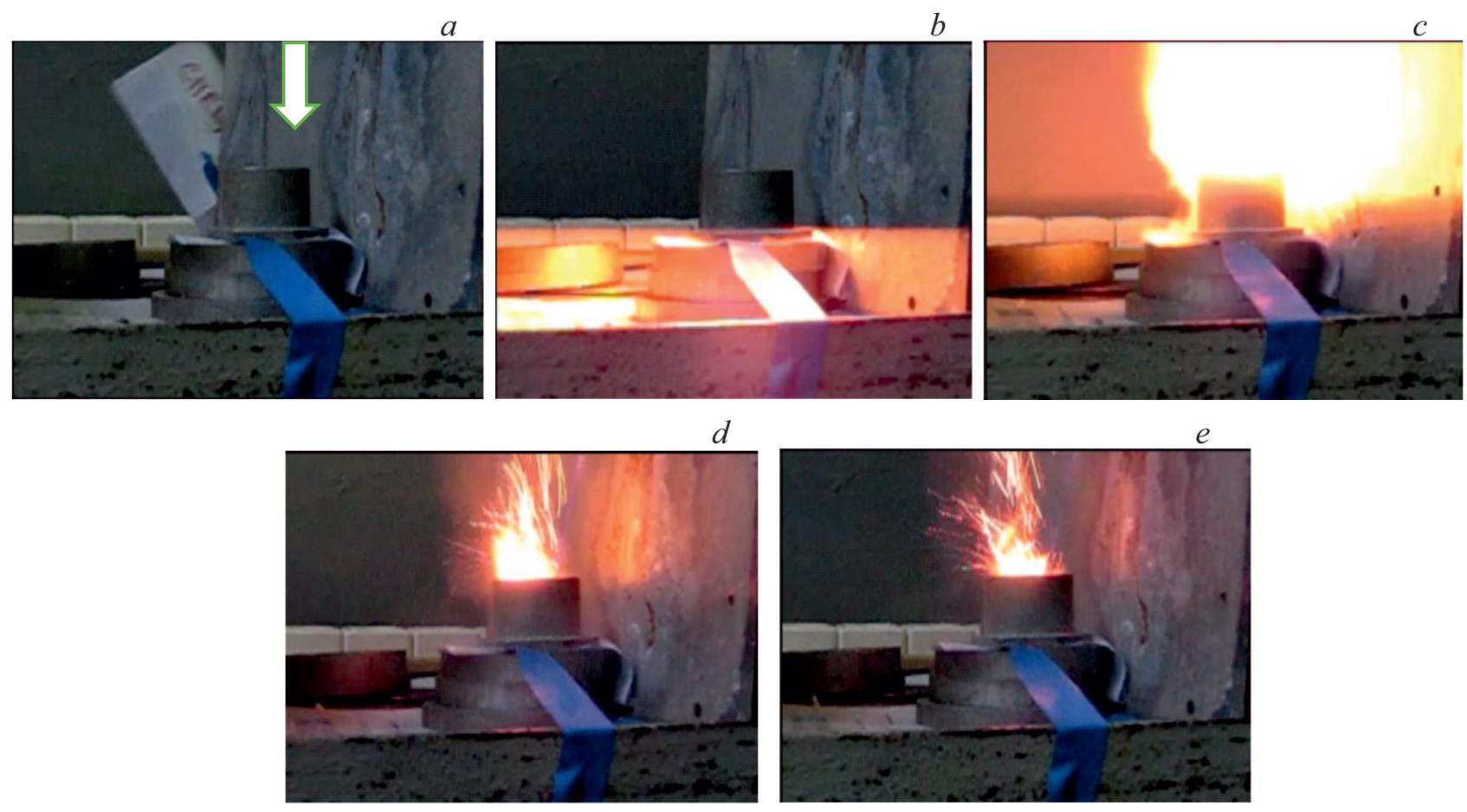

Рис. 1. Последовательность процесса взрывчатого превращения в энергокомпозите (nanoporSi+ $\mathrm{Ca}(\mathrm{ClO} 4) 2)$ (стрелкой указано направление лазерного луча): $a-$ исходное состояние; $b-$ предварительное свечение заряда; $c-$ горение заряда; $d, e-$ догорание заряда.

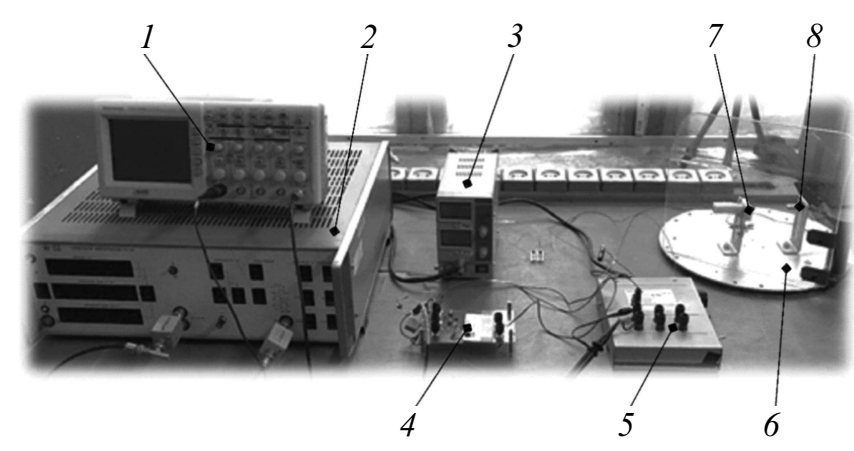

Рис. 2. Информационно-измерительный стенд: $1-$ осциллографф Tektronix TDS 2014; 2 - генератор импульсов Г5-60; 3 - источник тока HY1505 D; 4 - электронный ключ; 5 - стабилизатор напряжения Lm338; 6 - защитный экран; 7 - узел лазерного инициирования; 8 - фотодиод ФД-256.

\section{2. Методики и результаты экспериментов}

\section{Эксперименты с применением полупроводникового лазерного диода мощностью $100 \mathrm{~mW}$ с длиной волны $\lambda=405 \mathrm{~nm}$ (фиолетовый свет)}

Колпачок с зарядом устанавливали в оправку из оргстекла, оправку помещали в массивную обойму строго соосно лучу полупроводникового лазера. Луч лазера направлялся на отрытую поверхность заряда. Расстояние между лазером и колпачком $\sim 20 \mathrm{~cm}$. Как известно [10], полупроводниковые лазеры работают в режиме непрерывной генерации, и воздействие его луча на ЭНМ аналогично обыкновенному внешнему термическому воздействию.

Было проведено пять испытаний. Результаты всех испытаний положительные: во всех случаях в зарядах происходило взрывчатое превращение, что сопровождалось резким хлопком и интенсивным свечением, а также отсутствием остатков заряда в колпачке после проведения эксперимента. Последовательность развития процесса приведена на рис. 1.

Обращает на себя внимание свечение заряда на рис. $1, b$ через $\Delta t<10 \mathrm{~ms}$ (указано приблизительное время, поскольку установить более точное время не позволяла разрешающая способность видеокамеры $(90 \mathrm{fr} / \mathrm{s}))$ после воздействия лазерного луча. Поскольку со стороны фронтальной поверхности заряд свечения нет, то можно предполагать, что его воспламенение произошло в толще заряд, прилегающей к тыльной поверхности. Учитывая экстремально низкую мощность лазерного диода, можно предположить следующий сценарий развития процесса инициирования и зажигания заряда.

Лазерное излучение, проходя через заряд, переводит nanopor-Si и $\mathrm{Ca}\left(\mathrm{ClO}_{4}\right)_{2}$ в возбужденное состояние, в результате чего образуются активные атомы и радикалы. Когда количество активных центров на некой высоте заряда (ближе к тыльной поверхности) достигает кри- 


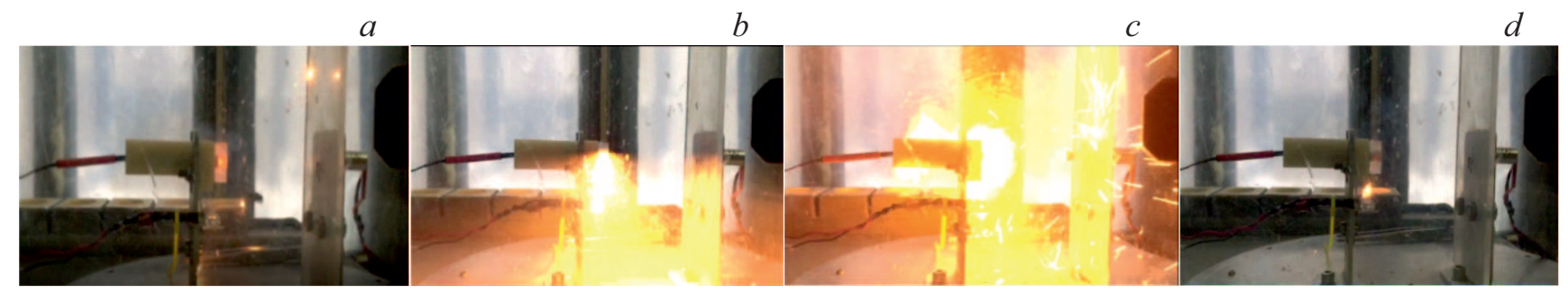

Рис. 3. Процесс взрывчатого превращения заряда ЭК-1: $a-$ начало реакции горения; $b, c-$ формирование обширной области горения; $d-$ догорание композита.

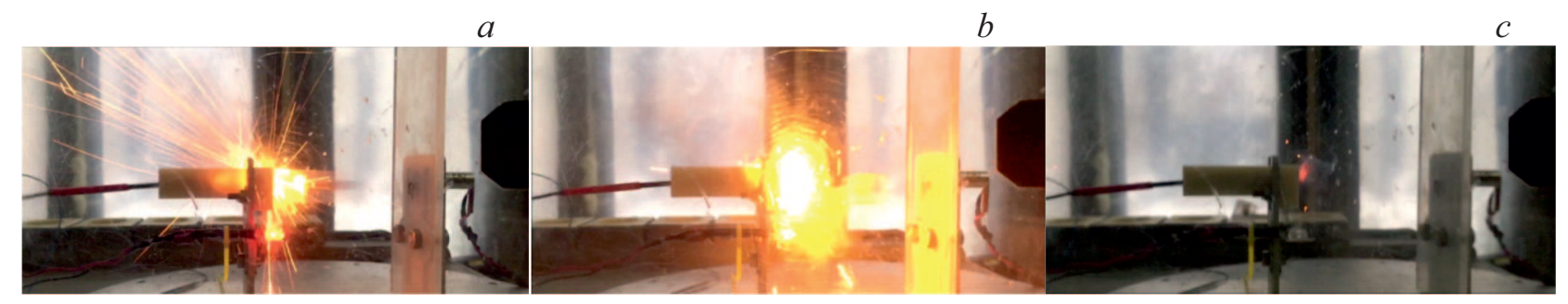

Рис. 4. Последовательность горения заряда ЭК-2: $a, b-$ формирование обширной области горения, $c$ - догорание заряда.

тического значения, необходимого для начала быстрой экзотермической реакции, происходит воспламенение заряда и последующее горение, вероятно, по цепному механизму [23].

Эксперименты с применением полупроводникового лазерного диода типа ECSE01-08-976 с длиной волны $976 \mathrm{~nm}$ (инфракрасное излучение) с выходной мощностью до $8 \mathrm{~W}$ проводились на информационноизмерительном стенде (рис. 2).

\section{3. Работа информационно-измерительный стенда}

Генератор импульсов Г5-60, осциллограф Tektronix TDS 2014 и источник питания HY1505 D питаются от сети $\sim 220 \mathrm{~V} 50 \mathrm{~Hz}$.

Генератор импульсов Г5-60 настроен на работу в режиме „““ на генерирование однократного прямоугольного импульса амплитудой $8 \mathrm{~V}$ и изменяемым масштабом длительности импульса от 0.1 до $1 \mathrm{~ms}$. Генератор импульсов Г5-60 синхронизируется с осциллографом Tektronix TDS 2014.

Осциллограф Tektronix TDS 2014 настраивается на регистрацию двух входящих сигналов. Первый поступает в момент подачи импульса на лазерный диод Focuslight FL-FCSE01-8-976, а второй с фотодатчика ФД-256 в момент воспламенения исследуемого пиротехнического состава.

Работа лазерного диода Focuslight FL-FCSE01-8-976 возможна только после подачи питания на стабилизатор напряжения Lm 338 и получения входного импульса от генератора Г5-60. За время импульса оптическое излучение лазерного диода воздействует на поверхность исследуемого энергокомпозита, вследствие чего происходит его воспламенение. Фотодатчик ФД-256 регистрирует световой поток воспламененного композита, который отображается в виде зависимости напряжения от времени на втором канале осциллографа Tektronix TDS 2014.

В условиях проведения испытаний на заряды из энергокомпозитов, изготовленных по вышеприведенной технологии, воздействовало лазерное излучение с постоянным потоком $q \approx 15 \mathrm{MW} / \mathrm{m}^{2}$. Было проведено пять испытаний. Во всех случаях воспламенения зарядов не наблюдалось. Таким образом, механизм, связанный с термическим эффектом лазерного воздействия, для исследуемого энергокомпозита (nanopor- $\left.\mathrm{Si}+\mathrm{Ca}\left(\mathrm{ClO}_{4}\right)_{2}\right)$ не работает.

В настоящее время ведутся поисковые работы, связанные с применением в ЭНМ наноразмерных форм углерода. Так, работе [5] был обнаружен эффект снижения порога лазерного инициирования при добавке ультрадисперсных частиц углерода в полимерсодержащий светочувствительный взрывчатый состав. В работе [24] при добавке графена резко повышалась чувствительность энергонасыщенной соли кобальта к воздействию сильноточного электронного пучка наносекундной длительности. В работе [25] рассматривалось применение графена в качестве перспективного легирующего компонента как к твердым ракетным топливам, так и первичным (инициирующим), и вторичным (бризантным) взрывчатым веществам. Поэтому было решено исследовать на предмет повышения чувствительности к инфракрасному лазерному излучению энергокомпозит nanopor$\mathrm{Si}+\mathrm{Ca}\left(\mathrm{ClO}_{4}\right)_{2}+$ graphene, о котором говорилось выше. 
$a$

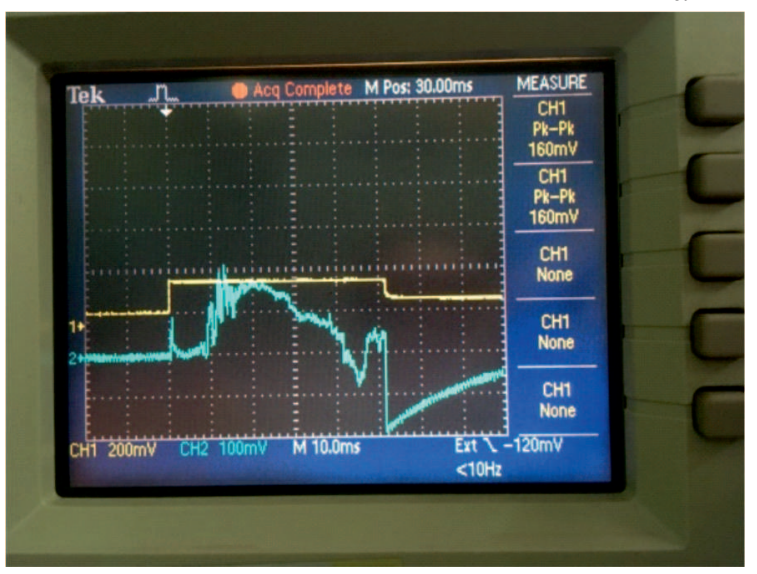

$b$

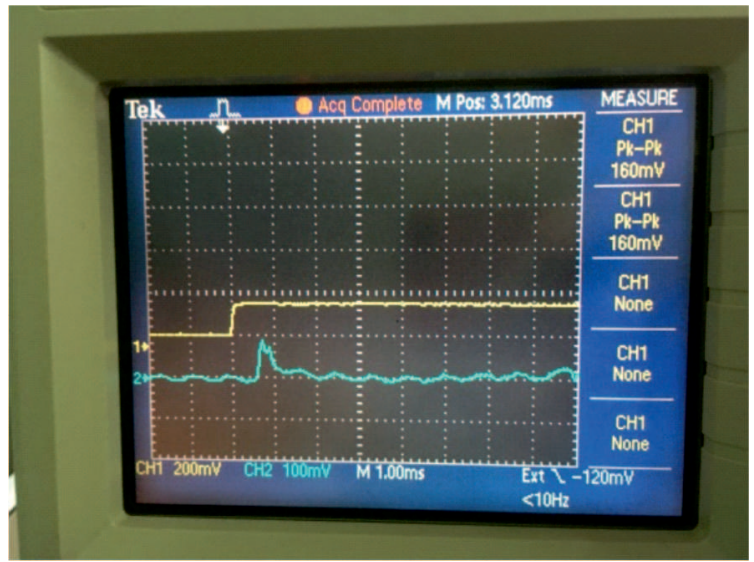

Рис. 5. Осциллограммы испытаний зарядов ЭК-1 (a) и ЭК-2 (b).

Было изготовлено два типа зарядов (см.выше) по три штуки каждого типа. При испытаниях во всех случаях наблюдалось взрывчатое превращение (воспламенение с сильным звуковым эффектом), которое можно интерпретировать как взрывное горение. Последовательность процесса взрывчатого превращения приведены на рис. 3 и 4.

Однако в случае ЭК-1 воспламенение с выходом фронта горения на свободную поверхность состава наблюдалось через $\sim 10 \mathrm{~ms}$ (рис. $5, a$ ), а в случае ЭК-2 через $750 \mu$ s (рис. $5, b$ ).

Таким образом, добавка порошка графеноподобного материала повышает воспламеняющую способность энергокомпозитов на основе нанопористого кремния к воздействию лазерного (инфракрасного) излучения. При этом если в случае классических взрывчатых составов при их лазерном инициировании поглощающая добавка не превышает 3-4 mass.\% (в случае превышения происходят отказы), то в нашем случае добавка составляет 20-30 mass. $\%$.

\section{Заключение}

По результатам проведенных экспериментов можно сделать следующие выводы.

1. В энергонасыщенном композите на основе нанопористого кремния, легированного бором, и перхлората кальция возбуждение взрывчатых превращений путем лазерного инициирования происходит при экстремально низком значении мощности лазерного диода $(0.1 \mathrm{~W})$ по механизму селективного фотосоздания активных частиц.

2. В рамках проведенных экспериментов возбуждение взрывчатых превращений в исследуемом энергокомпозите (nanopor- $\left.\mathrm{Si}+\mathrm{Ca}\left(\mathrm{ClO}_{4}\right)_{2}\right)$ за счет лазерного инфракрасного излучения не происходит.

Добавка в энергонасыщенный композит 20-30 mass.\% графеноподобного порошкового материала приводит к резкому увеличению чувствительности к инфракрасному лазерному излучению и возбуждению в композите взрывчатых превращений.

\section{Конфликт интересов}

Авторы заявляют, что у них нет конфликта интересов.

\section{Список литературы}

[1] Быстрое инициирование ВВ. Особые режимы детонации. Сб. научных статей / Под ред. В.И. Таржанова. Снежинск: Изд-во РФЯЦ-ВНИИТФ, 1998. 168 с.

[2] Илюшин М.А., Котомин А.А., Душенок С.А., Ефанов В.В. // Космонавтика и ракетостроение. 2017. № 1/35. C. $43-52$.

[3] Гребёнкин К.Ф. // Письма в ЖТФ. 1998. Т. 24. Вып. 20. C. $1-5$.

[4] Зегря Г.Г. Механизмы оже-рекомбинации в полупроводниковых наногетероструктурах и их влияние на характеристики лазеров. СПб.: Изд-во СПбГЭТУ „ЛЭТИ“, 2017. $216 \mathrm{c}$.

[5] Илюшин М.А., Целинский И.В., Угрюмов И.А., Козлов А.С., Долматов В.Ю., Шугалей И.В., Головчак А.Н., Веденецкий А.В., Королев Д.В., Осташев В.Б. // Химическая физика. 2005. Т. 24. № 10. С. 49-56.

[6] Алукер Э.Д., Белокуров Г.М., Кречетов А.Г., Митрофонанов А.Ю., Нурмухаметов Д.Р. // Письма в ЖТФ. 2010. Т. 36. Вып. 6. С. $80-85$.

[7] Антонов В.С., Летохов В.С., Шибанов А.Н. // УФН. 1984. T. 142. Вып. 2. С. 177-217.

[8] Луховицкий Б.И. Автореф. канд. дис. М.: МГУ им. М.В. Ломоносова, 2011. 26 с.

[9] Алукер Э.Д., Кречетов А.Г., Митрофанов А.Ю. // Вестник КемГУ. 2013. Т. 3. № 3 (55). С. 54-60.

[10] Герасимов С.И., Илюшин М.А., Кузьмин В.А. // Письма в ЖТФ. 2015. Т. 41. Вып. 7. С. 66-72.

[11] Лаптев Н.И., Мордасов В.И., Пойлов В.В., Сазонникова Н.A. // Известия Самарского научного центра РАН. 2009. T. 11. № 5 (2). С. 404-407. 
[12] Гуссейнов Ш.Л., Федоров С.Г. Нанопорошки алюминия, бора, боридов алюминия и кремния в высокоэнергетических материалах. М.: ТОРУС ПРЕСС, 2015. 256 с.

[13] Bezuidenhout H.C., Mukhopadhyay S. // Intern. J. Appl. Eng. Res. 2016. Vol. 11. N 16. P. 10465-10471.

[14] Зегря Г.Г., Савенков Г.Г., Морозов В.А., Зегря А.Г., Улин Н.В., Улин В.П., Лукин А.А., Брагин В.А., Оськин И.А., Михайлов Ю.М. // ФТП. 2017. Т. 51. Вып. 4. C. 501-506.

[15] Савенков Г.Г., Кардо-Сысоев А.Ф., Зегря Г.Г., Оськин И.А., Брагин В.А., Зегря А.Г. // Письма в ЖТФ. 2017. Т. 43. Вып. 19. С. 57-63.

[16] Савенков Г.Г., Зегря А.Г., Зегря Г.Г., Румянцев Б.В., Синани А.Б., Михайлов Ю.М. // ЖТФ. 2019. Т. 89. Вып. 3. C. $397-403$.

[17] Возняковский А.П., Савкин Д.И., Калинин А.В., Шугалей И.В., Крутов С.М., Мазур А.С. // Экологическая химия. 2016. Т. 25. № 3. С. $132-137$.

[18] Зегря Г.Г., Перель В.И. Основы физики полупроводников. М.: Физматлит, 2009. 336 с.

[19] Гусев О.Б., Поддубный А.Н., Прокофьев А.А., Яссиевич И.Н. // ФТП. 2013. Т. 47. Вып. 2. С. 147-151.

[20] Физика взрыва. Т. 1. / Под ред. Л.П. Орленко. М: Физматлит, 2002. $656 \mathrm{c}$.

[21] Зельдович Я.Б., Баренблатт Г.И., Либрович В.Б., Махвиладзе Г.М. Математическая теория горения и взрыва. М.: Наука, 1980. 478 c.

[22] Kovalev D., Timoshenko V.Yu., Künzner N., Cross E., Koch F. // Phys. Rev. Lett. 2001. Vol. 87. N 6. P. 068301-1-068301-4.

[23] Семёнов Н.Н. Избранные труды. Т. 1. Цепные реакции. Кн. 1. М.: Ин-т хим. физики им. Н.Н. Семёнова, 2004. $392 \mathrm{c}$.

[24] Савенков Г.Г., Морозов В.А., Илюшин М.А., Кач, М.А. // Письма в ЖТФ. 2018. Т. 44. Вып. 12. С. 39-44.

[25] Yan Q-L., Gozin M., Zhao F.-Q. Zhao, Cohena A., Pang S-P. // Nanoscale. 2016. N 8. P. 4799-4851. 